\title{
FINANCIAL RISK ATTITUDES, DEMOGRAPHIC PROFILES AND BEHAVIOURAL TRAITS: DO THEY INTERRELATE?
}

\author{
MOHD EDIL ABD SUKOR1, * \\ PAYAM NASEHI 2 \\ ERIC H.Y KOH ${ }^{1}$
}

Received: 31 January 2020 / Revised: 15 April 2020, 24 April 2020 / Accepted: 6 May 2020 Published online: 29 January 2021

(C) 2021 Faculty of Business and Accountancy, University of Malaya. All rights reserved.

\begin{abstract}
A B S T R A C T
Research aim: The paper addressed two objectives: examining the differences in behavioural traits with regard to risk attitudes, and explore the differences in financial risk attitudes with regard to demographic profiles of Malaysian investors.

Design/ Methodology/ Approach: Using the t-test and one-way analysis of variance (ANOVA), this paper investigates how differences in behavioural trait bias among 241 master of business administration students in Malaysia affect their financial risk attitudes.

Research finding: First, we find that the financial risk takers have higher levels of overconfidence, maximization, happiness, and trust than the risk-averse respondents. Second, in terms of demographics, we find that the following take significantly higher risks: men versus women, singles versus those who are married, and, those with lower income and less work experience. Besides, in terms of race, the Chinese are the greatest financial risk takers.

Theoretical contribution/ Originality: Both the behavioural traits and financial risk attitudes are new for a multicultural background market like Malaysia. Reflections on the findings suggest that the financial planners need to take cognisance of such relationships, tendencies and risk preferences so as to understand their client inclination and provide appropriate advice to their investor clients.

Research limitation/ Implication: Categories under the research design and sample selection can be further extended by considering more advanced research approach and a bigger size of sample respondents.
\end{abstract}

Keywords: Behavioural Finance, Behavioural Traits, Risk Attitudes, Financial Risk, Demographic Profiles

Type of article: Research paper

JEL Classifications: D14, D91, G41

\section{Introduction}

There has been an increased interest in studying the effects of cultural backgrounds and behavioural traits on business decision-making (Beugelsdijk \& Frijns, 2010; Guiso et al. 2006; Klement \& Miranda, 2012; Kuada \& Januleviciene, 2003; Nandan \& Saurabh, 2016; Veenhoven, 1994). For instance,

${ }^{1}$ Faculty of Business and Accountancy, University of Malaya, 50603 Kuala Lumpur, Malaysia. ${ }^{2}$ Chery Automotive, Tehran, Iran. *e-mail: mohdedil@um.edu.my 
a survey of participants in 69 countries found that demographic profile significantly affects business decision-making; the wealthier and those of higher social standing conduct their investment activities more happily and confidently (Veenhoven, 1994). In addition, financial advisors and portfolio managers should also consider the investor's behavioural traits such as happiness, overconfidence, regret and trust to assess one's risk attitude in setting expectations on investment decisions (Guiso et al., 2006). Moreover, Klement and Miranda (2012) and Park and Yao (2016) found that portfolio managers reckon investor behavioural traits are extremely important in making investment decisions and in financial risk taking. In light of these findings, this paper investigates the effects of demographic profile differences on investors' risk attitudes and how these attitudes affect their behavioural traits.

Demographic profiles and behavioural traits are important determinants of investors' risk attitudes for two reasons. First, an investor's behavioural traits affect his setting of expectations on economic outcomes (Guiso et al., 2006). Hence, it is important to understand how people's behavioural traits influence their thinking and deciding on investments. Second, financial advisors and portfolio managers play an important role in assessing investors' risk attitudes so as to help them achieve their goals at an acceptable risk level. Since financial advisors and portfolio managers are the major drivers of financial market performance (Gorman \& Sahlman, 1989; Jonsson, et al., 2017), information relating to the investors' financial risk attitudes should be useful in forming expectations of future financial market resilience. Although the demographic profile and behavioural traits influence the investors' financial risk attitudes, their association remains largely unexplored. This gap motivates the present study.

We study this association in the Malaysian market which was chosen for three reasons. First, Malaysia's uniqueness lies in its multi-ethnic and multicultural background. Therefore, a study of the Malaysian market may provide richer insights into the association among demographic profiles, behavioural traits and financial risk attitudes. Second, Malaysia has experienced strong financial growth in the past few decades; thus, the market has become increasingly important globally (New Straits Times, 2019). Third, there are many studies on the association among demographic profiles, behavioural traits and financial risk attitude in developed markets. But similar studies on emerging markets such as Malaysia are limited.

Our findings show that the following assume greater financial risks than their other counterparts in each demographic category comparison: men, unmarried, the Chinese, the lower income group, and those with less work experience. In terms of behavioural traits, this study finds that financial risk takers have higher levels of overconfidence, maximization, happiness and trust than their risk-averse counterparts. 
This study contributes to the existing literature on providing information for financial market players and regulators by offering evidence that the investors' financial risk attitude is connected to demographic profiles and behavioural traits. The remainder of this paper is organized as follows. Section 2 provides the literature review and the hypotheses tested in this study. Section 3 sets out the data and research design, while Section 4 provides the empirical results and analysis. Section 5 presents the overall conclusions.

\section{Literature Review}

This section discusses extant literature on financial risk attitude and develops hypotheses on how demographic profiles and behavioural traits are associated with financial risk attitude. We first discuss the different types of investors based on their risk profiles, followed by literature review related to financial risk attitude and then present the study hypotheses regarding how demographic profiles and behavioural traits are associated with financial risk attitude.

\subsection{General Discussion of Investor Types}

Among the earliest studies in which investor type was mentioned were conducted by Barnewall (1987) and Bailar et al. (1986). Bailard et al. (1986) propose a model that classifies investor personalities based on their level of confidence. Nevertheless, due to lack of generalization, the model was not well received by the literature. In a similar vein, Barnewall (1987) introduces more prevalent investor types' model. She distinguishes two relatively simple investor types: passive and active. Barnewall defines "passive investors" as those investors who have a greater need for security than they have tolerance for risk. Alternatively, "active investors" are individuals that have a higher tolerance for risk and have been actively involved in wealth creation through investment.

Pompian (2012) has developed a more recent investor types' model based on studies by Barnewall (1987) and Bailar et al. (1986). Pompian (2012, p. 2) explains:

One of the key observations from the model is that either end of the passive/active scale are clients who are susceptible to emotional biases and in the middle are clients affected mainly by cognitive biases or errors. This division makes intuitive sense when the investor types are considered.

He further classifies investors into four groups based on the following behavioral type and risk scale combinations: passive and low, passive and medium, active and medium, and active and high. Pompian (2012) has summarized that the first and second categories are believed to have relatively lower level of confidence, maximization and trust as compared with their last 
two counterparts. In explaining the differences in financial risk preference and behavioral factors of Malaysian investors with regards to demographic profiles and risk attitude, this study will adapt the discussed models.

\subsection{Financial Risk Attitudes, Demographic Profiles and Behavioural Traits}

While one of the earliest works on risk attitude came from Phoenix et al. (1959), the work of Ajzen and Fishbein (1977) is often cited as the seminal work on human risk attitude. Ajzen and Fishbein were the first to claim that behavioural norms affect people's risk attitude and subjective norms. Their work has been followed by a series of other studies, notably Dyer and Sarin (1982), who find that risk attitude is strongly related to a variety of corporate decision-making styles and managerial points of view. They argue that these differences arise from different approaches to perceiving the marginal values of possible outcomes and uncertainties.

Since risk attitude is not directly observable, researchers and financial players attempt to infer investors' risk attitudes from various models which study the effects of the respondents' demographic profiles or behavioural traits. One such model is the risk return framework introduced by Sarin and Weber (1993) to estimate people's risk attitude. The model employs the auction theory and observes how people react in auction markets. They find that people become more risk averse when they lack information or prior experience on the item on which they bid. They also argue that the results are useful in understanding some phenomena in the insurance and equity markets. Another is the conjoint expected risk (CER) model used in a study of cross-cultural differences in the perception of financial risks in Hong Kong, Taiwan, the Netherlands, and the U.S. (Bontempo et al., 1997). The authors found that the respondents from Hong Kong and Taiwan were more sensitive to the magnitude of potential losses than that for positive outcomes. Likewise, Statman (2008), in studying how demographic profiles affect investment decisions, found that people's risk aversion or risk seeking depends not only on their wealth, but also on their culture. Meanwhile, Ryff (1991) examines the correlations among level of education, happiness, and decision-making style. Using a subjective well-being index (SWB), she finds that level of education and happiness have meaningful correlations with occupation risk status. Similarly, Baker et al. (2019) finds that occupation and investment experience are the most important demographic variables that relate to the behavioural biases of individual investors in India. To the extent that marital status affects people's risk attitude, Diener et al. (1999) study the relationship between marriage and psychological factors concerning life circumstances in producing happiness and better investment decisions. They find that marriage has greater emotional benefits for men, but that, overall, there is no significant difference between married men and married women with respect to investment decisions. In 
contrast, Byrnes et al. (1999), who compare risk-taking tendencies of males and females through a meta-analysis of 150 studies, find that men are greater financial risk seekers than women.

Moreover, Weber and Johnson (2006) find that people's age and experience affect their financial decision making and risk taking. Older and more experienced people are more confident and are greater risk seekers than their younger counterparts. In a study on 795 higher education employees, Dulebohn and Murray (2007) find that level of education affects people's financial risk attitude. People with a higher level of education show a greater risk appetite. Likewise, a study of a group of low-income Australian households also find a strong positive relationship between a person's level of education or financial literacy and his financial decision-making process (Fry et al., 2008). More recent studies on the association between demographic profile and financial risk attitude include Albaity and Rahman (2012), Rieger et al. (2014) and Vieider et al. (2012). Vieider et al. (2012) study the association between income level and financial risk attitude among 3,025 respondents from 30 different countries and find that, within countries, risk tolerance is positively associated with personal income. Arianti (2018), Rieger et al. (2014) and Tanaka et al. (2010) report similar findings. Albaity and Rahman (2012) examine the demographic profile's influence on 416 undergraduate student respondents' financial risk attitude in Malaysia. Similar to Byrnes et al. (1999), they find that men are greater risk takers than women.

Meanwhile, some studies also show that behavioural traits play a role in determining financial risk attitude. For instance, Blaine and Crocker (1993) and Chen and Handley-Schachler (2016) find that wealthier and happier persons are more likely to take risks and tend to perform better in their investments. Next, Burks et al. (2009) and Wu et al. (2011) find that behavioural traits like cognitive skills influence the investment decision-making process. They argue that cognitive skills cause people to have different approaches to risky circumstances, such that people with high cognitive skills are more eager for risky investments.

Similarly, more recent studies have showed that risk tolerance, investor personality and behavioural finance biases are significantly related to each other. For example, Dickason and Ferreira (2018) provide evidence that investors with a high-risk tolerance level are subject to self-control bias. In a different study, Otuteye and Siddiquee (2019) argue that active investors tend to have lower performance than passive investors mainly due to cognitive and emotional factors. Kishan and Alfan (2019) on the other hand, find that the usage of financial statement for investment decision-making is higher among investors with higher degree of confidence. 


\subsection{Hypotheses}

The findings regarding the effect of demographic profiles and behavioural traits on financial risk attitude can be summarized as follows. First, the empirical results are mixed with some suggesting that some demographic profiles and behavioural traits affect a person's financial risk attitude. Second, much of the existing work has focused on developed markets. There appears to be limited published research examining the associations among demographic profiles, behavioural traits, and financial risk attitude in emerging markets and more so multi-racial countries like Malaysia. The only known exception is Albaity and Rahman (2012) who study the risk attitudes of undergraduate students in Malaysia. This paper aims to investigate whether there are any differences in financial risk preference and behavioural traits of Malaysian investors with regard to demographic profiles and risk attitude. Drawing from the preceding discussions, we develop two hypotheses as follows.

H1: People with different risk attitudes have different behavioural traits.

H2: People with different demographic profiles have different financial risk attitudes.

\section{Data and Methodology}

This study is a quantitative and empirical assessment of the association among demographic profiles, behavioural traits, and financial risk attitudes. This study follows the methodological analyses of Albaity and Rahman (2012) and Statman (2008) but extends those studies by investigating the association between demographic profiles, behavioural traits and financial risk attitudes together. Also, unlike Albaity and Rahman (2012) who studied undergraduates, this study employs a convenience sampling approach of Master of Business Administration (MBA) students from two selected universities in Malaysia i.e., Universiti Malaya (UM) and Universiti Teknologi Malaysia (UTM). These two universities were chosen due to convenience and the authors' access to the respondents through personal contacts. Nevertheless, we believe that the sample of students from these two universities are representatives because these MBA students would have some work experience, income and savings. They also have knowledge and interest in business and financial matters. They would be knowledgeable respondents because they can relate to decisions on investments and financial risk attitudes.

We employ the student's $t$-tests and analysis of variance (ANOVA) to study the differences in financial risk attitudes across different demographic profiles and behavioural traits. Drawing from the findings of our literature review, we measure and compare financial risk attitudes across five demographic variables (i.e., gender, marital status, race, level of income, and work experience) and test the effect of individual risk attitude on six behavioural traits (i.e., luck, overconfidence, regret, maximization, happiness, and trust). A questionnaire 
survey is implemented as the method of data collection. A 10-point Likert scale is used for each item, with higher levels of willingness to take a financial risk indicated by higher scores on the scale.

We also conducted a pilot study involving 11 males and 19 females' student to ensure that the contents of the questionnaire were understandable. The reliability of the pilot questionnaire was assessed using Cronbach's alpha and corrected item-total correlations before we handed out 300 questionnaires to the respondents. Of the 300 questionnaires, 241 (80.33\%) were completed satisfactorily where majority of them (224) are UM students. This high response rate of $80 \%$ exceeds the average of $48 \%$ obtained for studies published in 17 refereed academic journals (Baruch \& Holtom, 2008). The respondents are asked to indicate their financial risk attitude (1-risk taker and 2-risk averse) and to rate their level of agreement or belief in each of the six behavioural variables on a 10-point Likert scale. For example, in order to know whether someone believes that success in picking stocks that earn higher-than-average returns is due to skill or luck, the following scale was given: '1. Strongly believe that success is due to skill' to ' 10 . Strongly believe that success is due to luck'.

Table 1: Sample summary statistics

\begin{tabular}{llll}
\hline Demographic Profile & Category & No. of Respondents & Percentage \\
\hline Gender & Male & 100 & 41 \\
Marital Status & Female & 141 & 59 \\
\multirow{5}{*}{ Race } & Married & 89 & 37 \\
& Single & 152 & 63 \\
& Malay & 57 & 24 \\
& Chinese & 96 & 40 \\
& Indian & 46 & 19 \\
& Other & 42 & 17 \\
& < RM2000 & 30 & 12 \\
& RM2000-RM3999 & 64 & 27 \\
& RM4000-RM5999 & 78 & 32 \\
& RM6000-RM7999 & 28 & 12 \\
& RM8000-RM9000 & 23 & 10 \\
& $>$ RM10000 & 18 & 7 \\
Work Experience & 0-5 years & 103 & 43 \\
& 5-10 years & 99 & 41 \\
& $10-15$ years & 33 & 14 \\
& 15-20 years & 4 & 2 \\
& $>$ 20 years & 2 & 1 \\
\hline
\end{tabular}

Table 1 presents the descriptive statistics for this study sample. The respondents had varied demographic profiles. In terms of gender and marital status, the respondents were fairly distributed on an approximate 40:60 split between male to female and married to single ratios respectively. They also came from different ethnic groups. Although those of Chinese descent formed 
the largest group (40\%), they did not dominate the sample because each of the other ethnic groups comprises approximately $20 \%$ of the sample. In terms of income and work experience, those in the upper end of the spectrum form the minority and seems a reasonable reflection of the population.

\section{Empirical Results and Discussion}

\subsection{Risk Attitude and Behavioural Trait Bias}

Table 2 shows the differences in the mean scores of the behavioural bias variables for the risk-taking and the risk-averse respondents. We analyse the results under three categories. First, the risk takers record significantly higher scores for the variables of overconfidence, maximization and trust. Overconfidence bias entails being too optimistic or bullish on one's ability to pick stocks whose returns are likely to outperform the market. The risk takers may be more or too confident of the accuracy of the information available to them or their analytical prowess. Hence, the risk takers may be more confident than their risk averse counterparts, similar to those found in most prior studies (He, 2020; Koebel et al., 2015). Next, maximization relates to wanting the best and not settling for second best returns. Risk averse investors tend to fear risks and would not be inclined to stretch their chances to get the highest returns. Conversely, the risk takers may be willing to assume higher risks so as to maximize the chances for the highest returns. This is similar to the findings of studies such as Pan and Statman's (2012) study of American men and women but differ from Statman's (2015) study across 23 countries. Finally, trust involves taking on risks when dealing with non-family members. It is also likely that the risk takers would be willing to assume higher risks in trusting others as compared with the risk averse respondents. Those who are constrained by time (this includes busy executives pursuing MBA studies) and invest in instruments for which they have less knowledge would depend on and place more trust on the more knowledgeable experts (Olsen, 2012).

Second, contrary to our expectations, the risk takers are significantly happier (or contented) than their risk averse counterparts. This seems to contradict our first finding that the risk takers are more inclined towards wanting to maximize their returns and not settle for second best. Nonetheless, this finding seems consistent with previous research which does not reveal a clear cut relationship between happiness and risk attitude. Other factors such as the country's overall wealth and the individual's perceived wealth sufficiency affect this happiness/risk attitude relationship (Albaity \& Rahman, 2012).

Third, the scores for luck and regret do not significantly differ between the risk takers and risk averse respondents. This suggests that on average, the respondents are slightly more inclined to attribute successful investments with 
their own skills (mean scores of 4.11 and 4.23 for risk takers and risk averse respondents respectively) rather than luck. In comparison, a US-based study found that higher risk-tolerant investors tend to "attribute success [more] to luck [over skill]" because "a belief that successful outcomes of choices depend on luck more than on skill reduces responsibility for choices" Pan and Statman (2012, p. 60). But the respondent base may differ because the US-based study's respondents' age range from 18 to over 55, i.e. some may not even have an undergraduate degree and some are in the near- or post-retirement era. Our study, however, surveys MBA students, i.e., those who already have their first degrees and are way below retirement age. Moreover, our respondents are students of reputable universities and hence, they are probably more confident of, and rely more on, their skills rather than attributing the potential outcomes to luck. The greater reliance on skills is likely to be similar for both the risk averse and risk takers.

Likewise, in terms of regret aversion bias, our respondents, armed with their MBA studies background, are likely to explore the various options available before eventually deciding on one. They are also likely to evaluate their outcomes vis-à-vis those of other outcomes and feel bad if their decision seem suboptimal. Adapting from Solnik and Michenaud (2008), we may differentiate traditional risk-aversion from regret risk-aversion as follows: the former seeks to avoid returns volatility while the latter seeks to avoid potential regret in the future arising from sub-optimal risk/return trade-off decisions. In other words, most MBA students, regardless of whether they are risk-averse or risk-takers, tend to avoid potential regret in the future. Hence, the mean score of the risk takers does not significantly differ from that of the risk avoiders.

Table 2: Comparison of behavioural bias variables mean scores across different risk attitudes (risk takers vs risk averse)

\begin{tabular}{llllll}
\hline Behavioural bias variables & Risk taker & Risk averse & Mean diff. & $t$-stat & $p$-value \\
\hline Luck & 4.11 & 4.23 & -0.12 & -0.41 & 0.69 \\
Overconfidence & 5.82 & 5.18 & 0.64 & 2.50 & $0.01^{* *}$ \\
Regret & 6.09 & 6.06 & 0.03 & 0.10 & 0.92 \\
Maximization & 6.58 & 5.98 & 0.60 & 2.13 & $0.03^{* *}$ \\
Happiness & 7.09 & 6.60 & 0.49 & 2.15 & $0.03^{* *}$ \\
Trust & 5.45 & 4.66 & 0.80 & 3.22 & $0.00^{* * *}$ \\
\hline
\end{tabular}

*** $1 \%$ level of significance, ${ }^{* *} 5 \%$ level of significance, ${ }^{*} 10 \%$ level of significance

\subsection{Demographic Profiles and Risk Attitude}

Table 3 presents the results on the differences in financial risk attitude (measured by risk tolerance of $\mathrm{X} \%$ ) across the different demographic profiles. We asked the respondent to indicate his risk tolerance level of $\mathrm{X} \%$ as follows. We asked whether the respondent is willing to accept an opportunity to replace his current investment portfolio with a new portfolio that has a 50-50 chance of 
increasing by $50 \%$ and decreasing by a tolerable rate of $\mathrm{X} \%$. We measured this risk tolerance of $X \%$ through a 10-point Likert scale which ranges from '1. Highly risk averse $(X=3 \%)^{\prime}$ to ' 10 . Highly risk taker $(X=30 \%)^{\prime}$. Column 2 presents the mean risk tolerance measure $(X \%)$. Next, column 3 states the mean differences in risk tolerance across each paired demographic profile comparison. For instance, 'V1: Gender' shows a 2.54\% (i.e., 14.91 - 12.37\%) difference in risk tolerance between the male and female respondents. Columns 4 and 5 report the corresponding $t$ - and $F$ - statistics respectively. Column 6 presents the significance of the differences based on the $p$-values and asterisks marked.

Table 3: Difference in financial risk preference among demographic profiles

\begin{tabular}{|c|c|c|c|c|c|c|c|c|c|c|}
\hline \multirow[b]{2}{*}{ (1) } & \multicolumn{5}{|c|}{$\begin{array}{l}\text { Risk tolerance on investment } \\
\text { portfolio value }\end{array}$} & \multicolumn{5}{|c|}{ Risk tolerance on income } \\
\hline & $(2)$ & (3) & (4) & (5) F- & (6) p- & (7) & $(8)$ & (9) & (10) & $(11)$ \\
\hline Variable & $\begin{array}{l}\text { Risk } \\
\text { tol. }\end{array}$ & $\begin{array}{l}\text { Mean } \\
\text { diff. }\end{array}$ & t-stat & stat & value & $\begin{array}{l}\text { Risk } \\
\text { tol. }\end{array}$ & $\begin{array}{l}\text { Mean } \\
\text { diff. }\end{array}$ & t-stat & F-stat & p-value \\
\hline \multicolumn{11}{|l|}{ V1: Gender } \\
\hline Male & 14.91 & 2.54 & 2.45 & - & $0.02^{* *}$ & 13.88 & 2.65 & 2.69 & - & $0.01^{* * *}$ \\
\hline Female & 12.37 & & & & & 11.23 & & & & \\
\hline \multicolumn{11}{|l|}{ V2: Marital status } \\
\hline Married & 12.53 & -1.42 & -1.31 & - & 0.19 & 10.75 & -2.50 & -2.56 & - & $0.01^{* *}$ \\
\hline Single & 13.95 & & & & & 13.25 & & & & \\
\hline \multicolumn{11}{|l|}{ V3: Race } \\
\hline Malay & 10.46 & - & - & 5.82 & $0.00^{* * *}$ & 11.11 & - & - & 1.02 & 0.38 \\
\hline Chinese & 15.59 & & & & & 13.26 & & & & \\
\hline Indian & 12.04 & & & & & 11.87 & & & & \\
\hline Other & 14.00 & & & & & 12.36 & & & & \\
\hline \multicolumn{11}{|l|}{ V4: Income level } \\
\hline$<$ RM2000 & 12.60 & - & - & 1.52 & 0.18 & 12.10 & - & - & 3.04 & $0.01^{* *}$ \\
\hline RM2000-RM3999 & 15.28 & & & & & 14.95 & & & & \\
\hline RM4000-RM5999 & 13.45 & & & & & 11.95 & & & & \\
\hline RM6000-RM7999 & 12.07 & & & & & 11.43 & & & & \\
\hline RM8000-RM9000 & 13.43 & & & & & 11.09 & & & & \\
\hline > RM10000 & 10.17 & & & & & 8.00 & & & & \\
\hline \multicolumn{11}{|l|}{ V5: Work experience } \\
\hline $0-5$ years & 14.30 & - & - & 1.36 & 0.25 & 13.72 & - & - & 3.25 & $0.01^{* *}$ \\
\hline $5-10$ years & 12.86 & & & & & 11.60 & & & & \\
\hline $10-15$ years & 13.27 & & & & & 11.79 & & & & \\
\hline $15-20$ years & 11.25 & & & & & 3.75 & & & & \\
\hline$>20$ years & 3.00 & & & & & 3.00 & & & & \\
\hline
\end{tabular}

Column 6 shows that significant differences in risk tolerance exist in the gender and race categories. Males are higher risk takers than females because 
males are willing to accept a $14.91 \%$ drop in portfolio value as compared with only a $12.37 \%$ threshold for the females. This finding is consistent with those of most typical studies and is attributed to the males' tendency to be overconfident and to have higher testosterone levels and hence, a more aggressive status-seeking trait (Blake et al., 2019; Nofsinger et al., 2018). Meanwhile, those of Chinese descent assume significantly higher risks than the others. This probably reflects the tendency of the Chinese to feel insecure and hence, seek ways to accumulate wealth. This sense of insecurity is in turn shaped by the harsh experience encountered by their ancestors both in their ancestral homeland of China and also as migrants in their new host countries outside China (Koh, 2018; Redding \& Hsiao, 1990).

Next, we repeat the same process for the respondent's risk tolerance on income and present our findings in columns 7 to 11. Column 11 shows significantly different risk tolerance in all categories except for race. Under the 'V4: Income level' and 'V5: Work experience' comparisons, we see that respondents with lower incomes and work experience tend to be more risk tolerant. Likewise, males are willing to take higher risk in their income levels than females. While this study's results are consistent with Statman (2008), who finds respondents with lower income are greater risk takers, they are in contrast to Tanaka, Camerer, and Nguyen (2010) and Rieger, Wang, and Hens (2014), who find that risk tolerance is positively associated with personal income.

\subsection{Discussion}

Drawing from the results and analyses in sections 4.1 and 4.2, we further discuss our findings so as to facilitate formulation of the implications in a more granular way. In our survey of 241 MBA students in two Malaysian universities, we find that the risk-taking investors are significantly more bias than their risk-averse counterparts in the following four behavioural biases: overconfidence, maximization, trust, and happiness.

First, a person who is more willing to take higher risks in search for higher returns tend to over-estimate his ability to make wise investment decisions. He may run into dangers of taking unduly high risks with the illusion that he is making a good decision which will out-turn much better risk/return trade-offs. To mitigate this undesirable situation, an overconfident risk-taker investor should be informed and convinced that he would be better off with the advice of more objective investment professionals or other equally competent and trusted parties.

Second, a risk-taker tends to be a maximiser. He tends to aim for nothing less than the best returns even at the expense of generating poorer risk/return trade-offs. While the desire to maximize returns is understood, a maximiser needs to be advised that seeking the best returns may not always yield the best possible outcome. In fact, it may not be appropriate if he considers the bigger 
picture elements such as his unique circumstances, constraints, investment horizon and objectives. It may even be disastrous if an overly aggressive hunt for maximum returns leads to excessively risky investment decisions.

Third, a risk-taker tends to significantly trust others more than a risk-averse investor. He may do so without sufficiently careful consideration of his own unique circumstances, constraints and needs, best known to himself. Trusting others may also mean that he may not have carefully and objectively verified their assertions or recommendations. Hence, a risk-taker needs to be advised to conduct a more objective and holistic self-examination and also examination of information or advice received before making a decision.

Fourth, a risk-taker tends to be much happier than his risk-averse counterpart. Unlike the other findings which coincide with our expectations (based on our analyses of extant studies), we also cautioned that there are mixed findings because other factors may influence the risk-taker/happiness association. Nonetheless, our finding suggests that a risk-taker may be contented with accepting returns which do not commensurate with the risks assumed. Hence, a risk-taker may need to be prompted to critically question the adequacy of an investment's expected return if he were to take on a relatively riskier venture.

Next, our discussions in section 4.2 suggest that the following demographic groups tend to have higher risk tolerance (i.e., they tend to be the risk-takers). Risk tolerance is in turn measured in two aspects, namely variations in portfolio value (or capital gain) and variations in portfolio income (e.g., periodic dividend or interest or rental income). In terms of potential variations in investment portfolio value, the males and the Chinese seem to be risk-takers relative to their respective counterparts. In terms of tolerating potential variations in portfolio income, the males, the lower income group and those with fewer years of work experience tend to be risk-takers relative to their respective counterparts.

Pooling together the discussions pertaining to our findings in both sections 4.1 and 4.2 suggest the following. First, a male investor may tend to be a risktaker and hence, he may need to be more thoroughly assessed and/or cautioned as to whether he tends to exhibit biases in terms of over-confidence, maximization, happiness and trust. This needs to be done in both aspects of portfolio value and income variations. Second, the Chinese seem to be risktakers in terms of seeking to maximize portfolio value. But in terms of portfolio income, their risk tolerance level does not significantly differ from the other ethnic groups. Hence, a Chinese investor may need to be more thoroughly assessed and/ or cautioned as to whether he tends to be biased in terms of overconfidence, maximization, happiness and trust, in terms of his attitude towards potential variation in portfolio value. Third, the other two demographic groups also do not significantly differ from their respective counterparts in terms of 
portfolio value (but not income) variation. Hence, an investor in the lower income group or one with less work experience may need to be more thoroughly assessed and/or cautioned in terms of those four behavioural bias.

The preceding paragraphs discuss the inter-relationships between the risktaking attitude, the behavioural traits and also the demographic profiles. The reverse would also apply to the risk-averse investors who may tend to be less confident, less striving for the best returns, less happy and less trusting, and belong to the other demographic groups. We summarise these discussions in in Figure 1.

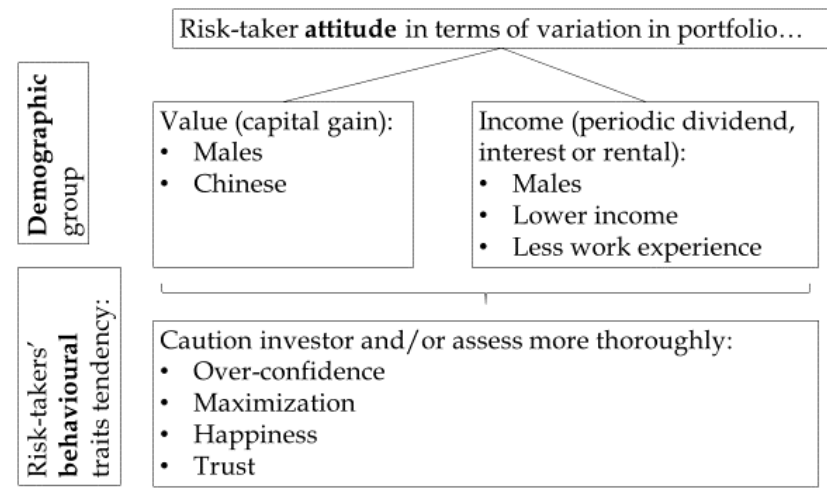

Figure 1. The inter-relationships between financial risk attitudes, demographic profiles and behavioural traits

\section{Conclusion}

This paper set out to examine whether investors' behavioural traits differ across those with different risk attitudes, and whether their risk attitudes differ according to their demographic profiles. A review of extant literature suggests different categorization approaches and mixed empirical findings. Moreover, published works tend to be in the developed markets context. Little has been published in the emerging market contexts. Hence, we adapted a questionnaire and surveyed 241 master of business administration (MBA) students in two major Malaysian universities.

Using the $t$-test and one-way analysis of variance (ANOVA), our analysis suggests two findings which in turn address our two research objectives. First, the financial risk takers (as opposed those who are risk averse) tend to have higher levels of overconfidence, maximization, happiness, and trust. Second, in terms of demographics, we find that the following take significantly higher risks: men versus women, singles versus those who are married, and, those with lower income and fewer years of work experience. Besides, in terms of race, the Chinese are the greatest financial risk takers. 
Our findings present implications for researchers, practitioners and public policymakers as follows. For researchers, the empirical findings provide support for application of the growing field of behavioural finance to an understudied emerging market context. Malaysia provides an interesting study context not only because of its rapid development but also because of its diversity in culture and racial settings. Future research may consider enhancing or refining the categories employed for classifying investors' risk attitudes, behavioural traits and demographic profiles. Besides, a larger and more diverse sample and post-survey interviews may provide richer insights. In addition, future research may study different investor categories such as active and passive investors, following Bailard et al. (1986), Barnewall (1987) and Pompian (2012).

Next, for practitioners, the financial planners may consider the following three points as they adapt the models (largely based on those from developed markets) to clients in emerging markets such as Malaysia. First, investors who tend to be overconfident, maximize outcomes, seek happiness and are more trusting would also tend to take higher risks. Second, a more educated and career-advancing investor is likely to believe more in his own skills and seeks to avoid regret. Third, demographic differences are likely to impact financial risk attitude. These considerations include gender, marital status, ethnicity, income level and length of work experience. Therefore, financial planners need to take cognisance of such investor tendencies and risk preferences. This would help the financial planners understand their client inclination and provide appropriate advice to their respective investor clients.

Finally, public policymakers may consider requiring financial planners to conduct a more thorough examination of, and discussion with, their clients, in terms of their financial risk attitudes, demographic profiles and behavioural traits. This is to facilitate greater awareness and better protection for the investing public. Perhaps, public policymakers may be more wary in terms of our findings that investors of lower income levels and fewer years of working experience tend to take on more financial risks. Such investors may need to be more enlightened in terms of financial literacy awareness.

\section{Acknowledgments}

This study would like to acknowledge the financial support of the University of Malaya under the Equitable Society Research Cluster (ESRC) research grant RP011D-13SBS and Faculty of Business and Accountancy.

\section{References}

Ajzen, I., \& Fishbein, M. (1977). Attitude-behaviour relations: A theoretical analysis and review of empirical research. Psychological Bulletin, 84(5), 888-918. https://psycnet.apa.org/doi/10.1037/0033-2909.84.5.888 
Albaity, M., \& Rahman, M. (2012). Behavioural finance and Malaysian culture. International Business Research, 5(11), 65-76. https://doi.org/10.5539/ibr.v5n11p65

Albaity, M. S., \& Rahman, M. (2012). Gender, ethnicity, and religion and investment decisions: Malaysian evidence. Journal of Sociological Research,3(2), 502-519. https:// doi.org/10.5296/jsr.v3i2.2649

Arianti, B. F. (2018). The influence of financial literacy, financial behavior and income on investment decision. Economics and Accounting Journal, 1(1), 1-10. http://dx.doi.org/10.32493/eaj.v1i1.y2018.p1-10

Bailard, T., Biehl, D., \& Kaiser, R. W. (1986). Personal Money Management, Chicago: Science Research Associates.

Baker, H. K., Kumar, S., Goyal, N., \& Gaur, V. (2019). How financial literacy and demographic variables relate to behavioral biases. Managerial Finance, 45(1), 124-146. https://doi.org/10.1108/MF-01-2018-0003

Barnewall, M. M. (1987). Psychological characteristics of the individual investor. ICFA Continuing Education Series, 1987(2), 62-71.

Beugelsdijk, S., \& Frijns, B. (2010). A cultural explanation of the foreign bias in international asset allocation. Journal of Banking and Finance, 34(9), 2121-2131. https://doi.org/10.1016/j.jbankfin.2010.01.020

Blaine, B., \& Crocker, J. (1993). Self-esteem and self-serving biases in reactions to positive and negative events: An integrative review. In Self-esteem (pp. 55-85). Springer US.

Blake, D, Cannon, E., \& Wright, D. (2019). Quantifying loss aversion: evidence from a UK population survey. Discussion Paper PI-1912, The Pensions Institute, Cass Business School: London.

Bontempo, R. N., Bottom, W. P., \& Weber, E. U. (1997). Cross-cultural differences in risk perception: A model-based approach. Risk Analysis, 17(4), 479-488. https://psycnet.apa.org/doi/10.1111/j.1539-6924.1997.tb00888.x

Burks, S. V., Carpenter, J. P., Goette, L., \& Rustichini, A. (2009). Cognitive skills affect economic preferences, strategic behaviour, and job attachment. Proceedings of the National Academy of Sciences, 106(19), 7745-7750. https:/ / doi.org/10.1073/pnas.0812360106

Byrnes, J. P., Miller, D. C., \& Schafer, W. D. (1999). Gender differences in risk taking: A metaanalysis. Psychological Bulletin, 367-383. https:/ / psycnet.apa.org/doi/10.1037/0033-2909.125.3.367

Chen, C., \& Handley-Schachler, M. (2016). Investigation of variation between risk attitude and investment biases. The International Review of Financial Consumers, 1(1), 57-80.

Dickason, Z., \& Ferreira, S. (2018). Establishing a link between risk tolerance, investor personality and behavioural finance in South Africa. Cogent Economics and Finance, 6(1), 113. https:// doi.org/10.1080/23322039.2018.1519898

Diener, E., Suh, E. M., Lucas, R. E., \& Smith, H. L. (1999). Subjective well-being: Three decades of progress. Psychological Bulletin, 125(2), 276-302. https://doi.apa.org/doi/10.1037/00332909.125.2.276

Dulebohn, J. H., \& Murray, B. (2007). Retirement savings behaviour of higher education employees. Research in Higher Education, 48(5), 545-582. https://doi.org/10.1007/s11162$\underline{006-9038-Z}$

Dyer, J. S., \& Sarin, R. K. (1982). Relative risk aversion. Management Science, 28(8), 875-886.

Eduniversal (2015), Business School University Ranking in Malaysia 2015. Available at: http://www.eduniversal-ranking.com

Fry, T. R., Mihajilo, S., Russell, R., \& Brooks, R. (2008). The factors influencing saving in a matched savings program: Goals, knowledge of payment instruments, and other behaviour. Journal of Family and Economic Issues, 29(2), 234-250. https://doi.org/10.1007/s10834-008-9106-y 
Gorman, M., \& Sahlman, W. A. (1989). What do venture capitalists do?. Journal of Business Venturing, 4(4), 231-248. https://doi.org/10.1016/0883-9026(89)90014-1

Guiso, L., Sapienza, P., \& Zingales, L. (2006). Does culture affect economic outcomes? Journal of Economic Perspectives, 20(2), 23-48. https:// doi.org/10.1257/jep.20.2.23

He, J. (2020). Risk attitude, financial knowledge and commercial life insurance needs. Modern Economy, 11(1), 185-199.

Jonsson, S., Söderberg, I. L., \& Wilhelmsson, M. (2017). An investigation of the impact of financial literacy, risk attitude, and saving motives on the attenuation of mutual fund investors' disposition bias. Managerial Finance, 43(3), 282-298. https://doi.org/10.1108/MF-10-2015-0269

Kishan, K., \& Alfan, E. (2019). Malaysian individual investors: What are the factors that influence their financial statement usage?. Asian Journal of Accounting Perspectives, 12(1), 22-48. https://doi.org/10.22452/AJAP.vol12no1.2

Klement, J., \& Miranda, R. E. (2012). Kicking the habit: How experience determines financial risk preferences. The Journal of Wealth Management,15(2), 10-25. https://doi.org/10.3905/jwm.2012.15.2.010

Koebel, B., Schmitt, A., \& Spaeter, S. (2015). Do self-theories explain overconfidence and financial risk taking? A field experiment. Document de Travail no. 2015 - 04, Bureau d'economie theorique et appliquee (BETA) UMR7522.

Koh, E. H. Y (2018). Chinese-ness legacy? A study of ethnic Chinese entrepreneur-controlled banks in Malaysia. International Journal of China Studies, 9(1), 49-66.

Kuada, J. E., \& Janulevièienë, R. (2003). Perspectives on female entrepreneurs: A comparative review of studies in the west and the transitional economies. Transformations in Business and Economics, 2(4), 109-122.

Michenaud, S. \& Solnik, B. (2008). Applying regret theory to investment choices: Currency hedging decisions. Journal of International Money and Finance, 27, 677-694. https://doi.org/10.1016/j.jimonfin.2008.03.001

Nandan, T., \& Saurabh, K. (2016). Big-five personality traits, financial risk attitude and investment intentions: study on Generation Y. International Journal of Business Forecasting and Marketing Intelligence, 2(2), 128-150.

New Straits Times (2019). Strong GDP growth continues to highlight Malaysia's resilience. Available at: https://www.nst.com.my/business/2019/08/513518/strong-gdp-growthcontinues-highlight-malaysias-resilience-mof

Nofsinger, J. R., Patterson, F. M., \& Shank, C.A. (2018). Decision-making, financial risk aversion, and behavioral biases: The role of testosterone and stress. Economics and Human Biology, 29, 1-16. https://doi.org/10.1016/j.ehb.2018.01.003

Olsen, R. (2012). Trust: the underappreciated investment risk attribute. Journal of Behavioral Finance, 13(4), 308-313. https:/ / doi.org/10.1080/15427560.2012.735728

Otuteye, E., \& Siddiquee, M. (2019). Underperformance of Actively Managed Portfolios: Some Behavioral Insights. Journal of Behavioral Finance, 21(1), 1-17. https://doi.org/10.1080/15427560.2019.1692210

Pan, C. \& Statman, M. (2012). Questionnaires of risk-tolerance, regret, overconfidence, and other investor propensities. Journal of Investment Consulting, 13(1), 54-63.

Park, E., \& Yao, R. (2016). Financial risk attitude and behavior: Do planners help increase consistency? Journal of Family and Economic Issues, 37(4), 624-638. https:// doi.org/10.1007/s10834-015-9469-9

Phoenix, C. H., Goy, R. W., Gerall, A. A., \& Young, W. C. (1959). Organizing action of prenatally administered testosterone propionate on the tissues mediating mating behaviour in the female guinea pig 1. Endocrinology, 65(3), 369-382. https://doi.org/10.1210/endo-65-3-369 
Pompian, M. (2012). Behavioral finance and investor types. Private Wealth Management Feature Articles, 2012(1), 1-3.

Redding, S. G., \& Hsiao, M. (1990). An empirical study of overseas Chinese managerial ideology. International Journal of Psychology, 25, 629-641. https://doi.org/10.1080/00207599008247917

Rieger, M. O., Wang, M., \& Hens, T. (2014). Risk preferences around the world. Management Science, 61(3), 637-648. http://dx.doi.org/10.1287/mnsc.2013.1869

Ryff, C. D. (1991). Possible selves in adulthood and old age: a tale of shifting horizons. Psychology and Aging, 6(2), 286-295. https://doi.org/10.1037//0882-7974.6.2.286

Sarin, R. K., \& Weber, M. (1993). Effects of ambiguity in market experiments.Management science, 39(5), 602-615. http://dx.doi.org/10.1287/mnsc.39.5.602

Statman, M. (2008). Countries and culture in behavioural finance. In CFA Institute Conference Proceedings Quarterly, 25(3), 38-44.

Statman, M. (2015). Culture in risk, regret, maximization, social trust, and life satisfaction. Journal of Investment Consulting, 16(1), 20-30.

Tanaka, T., Camerer, C. F., \& Nguyen, Q. (2010). Risk and time preferences: linking experimental and household survey data from Vietnam. The American Economic Review, 100(1), 557-571. http://dx.doi.org/10.1257/aer.100.1.557

Veenhoven, R., \& Coworkers (1994). World database of happiness: Correlates of happiness. Erasmus University NL.

Vieider, F. M., Chmura, T., \& Martinsson, P. (2012). Risk attitudes, development, and growth: Macroeconomic evidence from experiments in 30 countries (No. SP II 2012-401). Discussion Paper, Social Science Research Center Berlin (WZB), Research Area Markets and Politics, WZB Junior Research Group Risk and Development.

Weber, E. U. and Johnson, E. J. (2006). Constructing preferences from memory. In The Construction of Preference (pp. 397-410). Cambridge University Press US.

Wu, W. Y., Lu, H. Y., \& Chen, L. T. (2011). The moderating roles of involvement and heuristics on advertising effectiveness: A study of financial advertisements. Asian Journal of Business and Accounting, 4(1), 1-21. 